\title{
FACTORS INFLUENCING SUICIDAL TENDENCIES IN PATIENTS WITH DIAGNOSIS OF ATTEMPTED SUICIDE IN MEDICAL HISTORY AND RELAPS PREVENTION
}

\author{
Kvetoslava Kotrbová1, Ivan Dóci², Lidmila Hamplová1, 3, Vít Dvořák1, Šárka Selingerová1, Veronika Růžǐčková1, \\ Šárka Chmelařová ${ }^{1}$ \\ 1Department of Public Health, Faculty of Health and Social Studies, University of South Bohemia in České Budějovice, České Budějovice, \\ Czech Republic \\ ${ }^{2}$ Faculty of Medicine, Pavol Jozef Šafárik University in Košice, Košice, Slovak Republic \\ ${ }^{3}$ College of Nursing, Prague, Czech Republic
}

\begin{abstract}
SUMMARY
Objective: The authors researched the incidence of suicidal thoughts and related factors in 123 patients of the psychiatric ward of the Hospital of České Budějovice with diagnosed attempted suicide in their medical history for the period from January 2013 - June 2015.

Methods: The research was carried out in two stages. At the beginning of the hospitalization, quantitative data collection was implemented using a semi-structured questionnaire, followed by qualitative research conducted with semi-structured phone conversation, based on previous patient's written consent. The research data were statistically processed to obtain information about the character of relations among individual characteristics. To quantify them, the Bayesian Network (BN) was constructed, and to identify relations among individual characteristics, the HillClimbing algorithm was used. Before deriving the network, variables were discretized. The network parameters were set based on a data matrix using the maximal plausibility method.

Results: The results of analysed set show that the probability of suicidal thoughts is high, achieving a value of 0.750 ( 0.781 for women and 0.724 for men). If the patient visits a contact centre for drug-addicted persons, the probability of suicidal thoughts decreases to 0.683 . If the patient visits a psychotherapist, the values of 0.736 are achieved. If a daily care centre is visited, the estimated risk rises to 0.832 and the probability of the patient repetitively attempting suicide is 0.606 . If the interviewed person regularly consumes alcohol, the probable relapse amounts to 0.616 . But if the person consumes alcohol from time to time, the probability rises to 0.701 . In case of abstinence, the probable relapse decreases to 0.565 .

Conclusions: The incidence of suicidal thoughts in observed patients was high, and the amount of risk was influenced by gender, by visiting follow-up care facilities, psychotherapy, and particularly by the frequency of alcohol consumption. Intermittent alcohol consumption is the highestrisk factor in connection with relapsing suicide. In case of psychiatric patients with attempted suicide in their medical history, all verified preventive and therapeutic procedures that can contribute to prevention of relapses should be used within follow-up professional care. Specific approach of the closest social environment, medical literacy of the population and state safety measures are important.
\end{abstract}

Key words: suicide, attempted suicide, alcohol, drugs, prevention, suicidal thoughts

Address for correspondence: K. Kotrbová, University of South Bohemia in České Budějovice, Faculty of Health and Social Studies, Department of Public Health, J. Boreckého 27, 37011 České Budějovice, Czech Republic. E-mail: kotrbova@zsf.jcu.cz

https://doi.org/10.21101/cejph.a4677

\section{INTRODUCTION}

From the perspective of basic values, the universal value of human life is the most important as the basic ethical maxim of our society. The right to life ranks among inalienable human rights. It is a right that must not be disposed even by its holder $(1,2)$. Attitudes to suicide have changed in the course of history; at present, such act provokes ambivalent responses in the environment, as it constitutes a destruction of one's own life, and life is a highly recognized value, but on the other hand, it is an act of free choice a human should have (3). The complicated attitude of current society to termination of one's own life is illustratively documented by the discussion on euthanasia that has been taking place for years already (4). The concept of suicidality includes suicidal thoughts and suicidal behaviour. Suicidal behaviour constitutes an act of deliberate self-inflicted injury with fatal (suicide) or non-fatal (attempted suicide) consequences. Habitual self-inflicted injuries like auto-mutilation, tobacco smoking and excessive alcohol consumption do not constitute attempted suicides $(5,6)$. In American studies, attempted suicide is described as a comprehensive act including several dimensions; the injury degree, lethality of the method used and the degree of suicidal intention are important $(6,7)$. European studies define suicide as intentional self-harming behaviour with suicidal intention (8). The incidence of suicides 
in the population differs by geographic areas, and changes can be observed in time. For example, Greece has historically ranked among countries with the lowest number of suicides ( 2.8 persons per 100,000 inhabitants), but from the outbreak of the economic crisis in 2007 to its drastic deepening and acceptance of austerity measures, the number of suicides has risen by more than $35 \%$ (9). In the Federal Republic of Germany, suicide is committed by approximately the same number of persons as the number of victims of traffic accidents; although the indicator has been changing in time too (10). The motivation for specific behaviour may be very varied. The needs inducing different relevant motives may be dispositional, but they may also develop in the course of life. The incidence of suicides is influenced by gender, age, education, social and economic situation, alcohol and drug consumption, as well as by personal bankruptcies or serious diseases, by loss of a close person, mental diseases, and by a number of strains (11).

Šteflová states that mental diseases represent the highest social and economic strain in the developed states, according to data of the WHO and the World Bank (22.0\% of losses, while cardiovascular diseases $20.4 \%$, and tumorous diseases $13.7 \%$ ). In the last ten years, the number of patients coming to psychiatric outpatient departments has increased by more than one third (5\% inhabitants are currently undergoing therapy). The most frequently treated diseases include mood disorders (increased by 109\%), neurotic problems (increased by 53\%) and dementia (increased by $64 \%$ ). Psychiatric diseases constitute the 2 nd highest strain in the WHO European region and they are the cause of $19.5 \%$ of total number of disability-adjusted life years. Out of the approximately 850 million people in the WHO European region, about 100 million people suffer from depressions, 21 million people suffer from disorders caused by excessive alcohol consumption, 7 million people are affected by Alzheimer's disease or other forms of dementia, and 4 million people suffer from schizophrenia. Suicides are the cause of about 60,000 deaths per year in the EU twenty-eight countries. In 2003-2011, men's standardised death rate (SDR) of self-inflicted injury with subsequent death in the Czech Republic distinctively surpassed the suicidality of men in the original fifteen EU countries. In 2011, the difference between SDR of suicides per 100,000 men of the EU 15 (value 14.3) and men of the Czech Republic (value 23.6) amounted to 9.3 deaths/100,000 men against Czech men; the difference of suicidality of women of the EU 15 and of the Czech Republic is insignificant (EU 15 women - SDR 4.3/100,000 women, Czech women - SDR 4.1/100,000 women) and it was approximately four times lower than that of men all along the observed period (13). Decreasing standard of living and increasing unemployment as society-wide social factors, but also psychological factors like loneliness, particularly in a specific period of life, are considered the factors increasing the suicide risk (14). Suicidal behaviour is frequent in people with schizophrenia who terminate their life by suicide in about $10 \%$ of cases (15). Under the age of 12 suicides are rare, the frequency increases in puberty and in early adulthood. Suicide is more frequently related to schizophrenia in adolescence (16). An older, but extensive epidemiological study carried out in the United States showed that almost one half of the inhabitants suffer from some mental disorder at some point of their life. Most frequently, such disorders include addiction to habit-forming substances $(26.6 \%)$, followed by anxiety disorders (24.9\%) and affective disorders (19.3\%). The score prevalence is $7.3 \%$ of population, according to the study by Kessler et al. (17). By the end of the last century, the WHO estimated, based on long-term trends, that in 2020 , about 1.53 million people in the world would die due to suicide and 10-20 times more people will attempt suicide. That constitutes, on average, one death every 20 seconds and one attempt each 1-2 seconds (18). The Czech Republic ranks among minority countries of the European Union that have not had any governmental programme of mental health care yet. That fact has led to unsystematic character of establishment of psychiatric institutions, missing or unequally deployed outpatient services, obsolete structure of inpatient care capacity and lack of community care facilities (19). From the perspective of expenses on mental health in the Czech Republic, the proportion of funds designated to mental health within public health care amounts to some $0.26 \%$ GDP, while in the EU it amounts to $2 \%$ GDP on average (20).

At present, the psychiatric care mostly takes place in psychiatric outpatient departments. According to the Institute of Health Information and Statistics of the Czech Republic, 2,834,000 interventions were carried out in the Czech psychiatric outpatient departments in 2013 . The number has increased by $38 \%$ since 2000. Unipolar depression of adults is the most frequent motive to visit a psychiatrist and one of the most frequently diagnosed psychiatric disorders $(21,22)$. Clinical mastering of the diagnosed cases is aimed at reducing or eliminating symptoms and at preventing relapses by administration of anti-depressants, psychotherapy and support treatment in form of social contact (talks, counselling, etc.). Swedish authors point out the necessity and the crucial importance of follow-up care for psychiatric patients with diagnosed schizophrenia, bipolar and unipolar disorder, who need such care particularly during the first two years after the attempted suicide (23). Patients with attempted suicide are permanently under high risk of recurrence, and that fact must be considered in the follow-up care.

In our study we observed the incidence of suicidal thoughts in patients of the psychiatric ward of the Hospital of České Budějovice with attempted suicide in their medical history for the period from 2012-2015.

\section{MATERIALS AND METHODS}

The basic set consisted of 292 patients (134 men, 158 women), who were hospitalized and underwent, voluntarily or in detention mode, systematic psychotherapy in the psychiatric ward of the Hospital of České Budějovice from January 2013 to June 2015. Their diagnoses at admission were: F22.9-18 (persistent disorder with delusions, NS), F23.2-10 (acute schizophrenia-like psychotic disorder), F32.9-49 (depressive phase of NS), F40-4 (phobic anxiety disorders), F41.1-31 (generalized anxiety disorder), F42-5 (obsessive-compulsive disorder), F43.2-70 (adaptation disorders), F45-2 (somatoform disorders), F43.9-103 (response to serious stress, NS). A part of the patients, specifically 123 (42\%), 66 men and 57 women of the basic set, agreed to participate in the follow-up part of the study. The minimum age was 15 years, the maximum age 57 years (median 36 years, arithmetic mean 34.95 years, standard deviation 8.08). The minimum age at the first attempted suicide was 13 years, the maximum age was 54 years (median of the set 32 years, arithmetic mean 31 years, standard deviation 8.31). 
The first part of the study was focused on several aspects including psychiatric family burden, current mental condition, economic and social situation, abuse of illegal habit-forming substances, frequency of alcohol abuse, family status, education, way of execution of the attempted suicide, repeatability of suicidal actions, motives for suicidal actions, etc. Based on their informed consent, they were contacted by phone after completed hospitalization and return to daily life. They were contacted after 2 months from discharge, a period to acclimatise to daily life. After that time, we asked whether they observed the suggestions applied during hospitalization. Most of the hospitalized patients had new or repeated anti-depressive or anti-psychotic medication. In the phone contact, the patients were asked about problems concerning the quality of life after the attempted suicide and after the follow-up hospitalization. The main questions were: whether they regularly went to their psychiatrist or psychologist, whether they had undergone hospitalization in a medical institution or whether they regularly went to psychotherapies, whether they observed the medication, how often they consumed alcohol, whether they suffer from suicidal thoughts, how they slept, and what their social and economic situation was like. The phone talks were structured according to prepared questions. In order to observe the patients' anonymity, the admission questionnaire and the follow-up questionnaire had the same identification number. Recorded answers were statistically evaluated. The research data were statistically processed to obtain further information on the character of relations among individual characteristics, and the Bayesian Network (BN) was constructed for their quantification. To derive them or to determine the $\mathrm{BN}$ topology (to identify relations among individual characteristics), the Hill-Climbing algorithm was used. Before deriving the actual network, variables were discretized. The network parameters were subsequently set based on a data matrix using the maximal plausibility method (37-39).

\section{RESULTS}

The following analysis is based on a set acquired from January 2013 to June 2015. The data set included answers from 123 patients in total, who had been repeatedly interviewed. They consisted of patients who had attempted suicide at least once; 66 men and 57 women answered the question complex repeatedly in the course of the study. The basic demographic descriptive characteristics of the set are stated in Table 1.

In order to obtain further information on the character of relations among individual characteristics, the Bayesian Network (BN) was constructed for their quantification. To derive them or to determine the BN topology (to identify relations among individual characteristics), the Hill-Climbing algorithm was used. Before actual derivation of the network, discretization was carried out for the following variables: year $(2013,2014,2015)$, patient's age categories $(0-15,15-20,20-25,25-30,30-35$, $35-40,40-45,45-50$, and 50-60), patient's age at the first attempted suicide categories $(0-15,15-20,20-25,25-30,30-35$, $35-40$, and 40-60) and for the variable of the number of attempted suicides $(0-1,1-6)$.

The network parameters were subsequently set based on a data matrix using the maximal plausibility method. The resulting Bayesian Network, i.e. the probability model, can be characterized through simultaneous probability: $\mathrm{P}$ (year, gender, age, diagnosis, hospitalization, medication, suicide, sleep, situation, partner, alcohol, drugs, psychiatrist, visits, age at first attempt, how many times) $=\mathrm{P}$ (year), $\mathrm{P}$ (psychiatrist), $\mathrm{P}$ (visits/psychiatrist), $\mathrm{P}$ (age/ visits), $\mathrm{P}$ (sleep/visits), $\mathrm{P}$ (medication/age, sleep), P (age of first attempt/age), $\mathrm{P}$ (situation/sleep, age of first attempt), $\mathrm{P}$ (alcohol/ medication), P (hospitalization/alcohol, psychiatrist), P (how many times/age, alcohol), $\mathrm{P}$ (partner/hospitalization, visits), $\mathrm{P}$ (gender/partner, alcohol, age at first attempt), P (drugs/partner, visits), $\mathrm{P}$ (diagnosis/gender, visits), $\mathrm{P}$ (suicide/gender, medication, visits, how many times).

The identified probability relations - connections are recorded in Figure 1.

In order to characterize topology of the acquired model, it can be stated that it contains 16 nodes (variables) and 26 oriented edges. The average value, so called "Markov blanket", amounted to 5.00. To create the Bayesian Network, 570 tests were needed. The average size of neighbourhood amounted to 3.25. The resulting identified topology of the Bayesian Network shows that suicidal thoughts of patients who attempted suicide in the past are related to the patient's gender, as well as to the number of attempted suicides and to whether the patients regularly go to an assistance centre (community centre, psychotherapy, day care centre). The resulting model also shows that suicidal thoughts are influenced by medication, i.e. whether the patient takes the

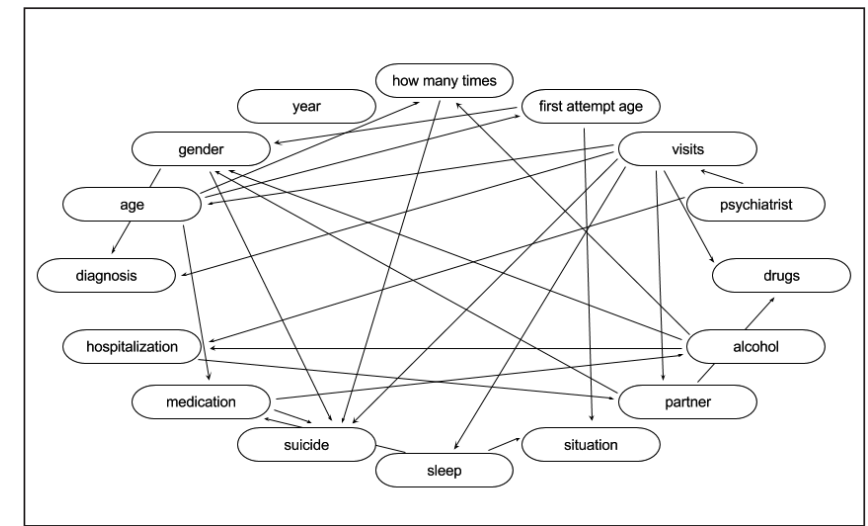

Fig. 1. Identified probability relations.

Table 1. Basic descriptive demographic characteristics

\begin{tabular}{|l|c|c|c|c|c|}
\hline Characteristics & Minimum & Median & Average & Standard deviation & Maximum \\
\hline Patients' age & 15 & 36 & 34.95 & 8.08 & 57 \\
\hline Patients' age at their first attempted suicide & 13 & 32 & 31 & 8.31 & 54 \\
\hline Number of attempted suicides & 1 & 2 & 2.049 & 1.10 & 6 \\
\hline
\end{tabular}


prescribed medication. It is worth mentioning that the $\mathrm{BN}$, in this case, identified a relation between the patient's medication and quality of sleep. As for the variable of the number of attempted suicides, it is influenced by the fact whether and how often the patient consumes alcohol and by patient's age. The model achieved a value of $\mathrm{BIC}=-11,277.72$.

The table shows the probability distribution for the "how many" variable, i.e. for the variable related to the number of attempted suicide, depending on how old the respondent was and to what level he or she consumed alcohol.

The subsequently implemented interviews and the exact inferences show the following facts: with respect to the whole set under analysis (at repeated interviewing of the same patients in the course of the study), the probability of the patient suffering from suicidal thoughts is estimated at 0.750 .

If a woman is concerned, then the probability of her having suicidal thoughts rises to 0.781 . If a man is concerned, the probability amounts to 0.724 .

If the patient visits a "CC", the probability of suicidal thoughts decreases to 0.683 . If the patient attends psychotherapy, the probability of incidence of suicidal thoughts in such patient is estimated at 0.736 , based on the observed data. If the patient visits a day care centre, then, somewhat surprisingly, the estimated probability of incidence of suicidal thoughts increases to 0.832 .

As for age, frequency of alcohol consumption and number of attempted suicides, the following findings can be derived: with respect to the whole set under analysis (at repeated interviewing of the same patients in the course of the study), the probability of the patient repeatedly attempting suicide is estimated at 0.606 .

If the patient regularly consumes alcohol, the probability of repeatedly attempted suicide amounts to 0.616 . If the patient reports alcohol consumption from time to time, the probability is estimated to 0.701 by the Bayesian Network. If the respondent reports no alcohol consumption, the probability of repeatedly attempted suicide decreases to 0.565 . It is thus obvious that particularly intermittent alcohol consumption and subsequent intoxication constitutes a considerable risk factor.

Table 2 shows conditioned probabilities related to the number of attempted suicides depending on the variables of age and alcohol consumption. The table shows the probability distribution for the "how many" variable, i.e. for the variable related to the number of attempted suicide, depending on how old the respondent was and to what level he or she consumed alcohol.

\section{DISCUSSION}

In our set, a difference in incidence of suicidal thoughts of psychiatric patients was found with respect to gender. The finding is in accordance with the conclusions of similar studies. Rodziński et al. analysed suicidal ideations of patients before and after hospitalization in psychiatric hospital. They found that women had more suicidal thoughts and higher intensity of neurotic symptoms than men; they showed obsessive-compulsive neurasthenic symptoms more frequently and they reported more often uncontrollable hunger. The authors suggest paying more attention in prevention of suicides to the women with the above stated symptoms (24).

According to our study, the frequency of suicidal thoughts is considerably influenced by follow-up care. Our study shows the need of comprehensive follow-up care for psychiatric patients with suicidal thoughts, which corresponds with the results of many studies. Stanley et al. implemented an innovative short two-stage post-hospitalization intervention aimed at decreasing the frequency of suicidal thoughts and at improving cooperation during treatment, including the patient's safety planning and structured phone conversations with 95 veterans who had sought out acute psychiatric help due to suicidal thoughts at least twice in the preceding 6 months. The intervention significantly reduced the number of hospitalizations in the subsequent three months, as compared to the group of veterans in which the intervention had not been implemented (25). According to our study a significant risk factor of relapsing suicide represents alcohol, particularly binge-drinking. In world literature, the above statement is confirmed by a lot of studies and the fact is generally accepted by experts (26-29). A significant correlation between suicidal behaviour and alcohol was also found by Wetterling and Schneider whose study demonstrated that persons with suicidal behaviour were often acutely intoxicated by alcohol (30). A meta-analysis of studies performed by Darvishi et al. has shown that excessive alcohol consumption significantly increases the risk of suicidal thoughts, attempted suicides and finished suicides and that it can be considered one of the frequent causes of premature violent deaths (31). Consoli et al. examined risk and protective factors of suicidality 6 months after hospitalization in adolescents who had been hospitalized due to attempted suicide. The results show that after discharge from hospital, risk factors for the adolescents with one attempted suicide in their medical history included mainly depression and despair. Protective factors included high work load and higher motivation to work or to improve their school (study)

Table 2. Conditioned probabilities

\begin{tabular}{|c|c|c|c|c|c|c|c|c|c|c|}
\hline \multirow[b]{2}{*}{ Alcohol } & \multirow[b]{2}{*}{$\begin{array}{l}\text { Number of } \\
\text { attempted suicides }\end{array}$} & \multicolumn{9}{|c|}{ Age categories of patients } \\
\hline & & $0-15$ & $15-20$ & $20-25$ & $25-30$ & $30-35$ & $35-40$ & $40-45$ & $45-50$ & $50-60$ \\
\hline \multirow{2}{*}{ Yes } & $0-1$ & - & 1.0 & 0.95 & 0.62 & 0.0 & 0.47 & 0.35 & 0.2 & 0.87 \\
\hline & $1-6$ & - & 0.0 & 0.05 & 0.37 & 1.0 & 0.53 & 0.65 & 0.8 & 0.13 \\
\hline \multirow{2}{*}{ No } & $0-1$ & - & 0.82 & 0.53 & 0.78 & 0.43 & 0.27 & 0.27 & 0.0 & 0.0 \\
\hline & $1-6$ & - & 0.18 & 0.47 & 0.22 & 0.57 & 0.73 & 0.73 & 1.0 & 1.0 \\
\hline \multirow{2}{*}{$\begin{array}{l}\text { From time to } \\
\text { time }\end{array}$} & $0-1$ & 1.0 & 1.0 & 0.0 & 0.37 & 0.29 & 0.21 & 0.35 & 0.41 & 0.0 \\
\hline & $1-6$ & 0.0 & 0.0 & 1.0 & 0.63 & 0.71 & 0.79 & 0.65 & 0.59 & 1.0 \\
\hline
\end{tabular}


results (32). Tarolla et al. state, in accordance with the findings of our study, that attempted suicide is one of the most serious predictors of committing suicide in the future. Other significant predictors in their study included unemployment and low job position, inadequate to higher education (underemployment) (33). The relations between the frequency of use of follow-up care after hospitalization due to attempted suicide and between the socio-demographic characteristics of patients were examined by Yen et al. whose study monitored 99 patients after discharge from psychiatric hospital after attempted suicide. The results of their study show that weak functioning at the beginning of the monitoring period was connected with higher use of intensive care and lower use of follow-up outpatient care. $19 \%$ of adolescents in total attempted suicide anew in the monitored six-month period. The authors declare that patients who were psychiatrically hospitalized after attempted suicide require longer psychiatric hospitalization, better planning of passage from hospitalization to outpatient care and more intensive outpatient care (34).

Norheim et al. consider psychiatric disorders the most frequent cause of suicidal behaviour and regard psychotherapy as the most suitable form of therapy; however, they point out that patients with other comparably serious disorders are more systematically monitored (23).

\section{CONCLUSIONS}

Our study has clearly shown the need of follow-up care to influence the frequency of suicidal thoughts. Particularly intermittent alcohol consumption and the subsequent intoxication of the patient were proved to be a significant risk factor of relapsing suicide. The WHO report "Preventing suicide: a global imperative" refers to suicide as a huge problem of public health that has been tabooed for a long time and whose solution consists primarily in effective prevention. The member states have undertaken the task to reduce the number of suicides by $10 \%$ worldwide by the year 2020 (36). Timely identification of risks, social prevention, medical intervention, and regulatory measures at state level play an important role in prevention of suicides. Higher health literacy of professional and lay public in this area is also a path to influence the incidence through specific knowledge of risk factors and thus timely identification of imminent suicide. Social prevention consists of improvement of social and economic conditions for inhabitants with the lowest income and risk behaviour, as well as of educational programmes for the public, support to self-help groups and volunteer organizations (e.g. Alcoholics Anonymous, etc.). The state regulatory measures include restriction of accessibility of potential lethal substances like sedatives, anti-depressants and paracetamol through well considered prescription, as well as tightening conditions for possession of weapons and safety technical measures. The medical intervention includes timely detection and mastering of depressions, mapping of and timely intervention in risk factors (alcohol consumption and abuse of illegal habit-forming substances), etc. There is a large area of activity particularly for primary-care physicians, as psychological autopsies show that $70 \%$ of self-murderers visited their physician in the month before their death, and $40 \%$ did it in the week before their suicide. The solution lies in deeper cooperation of psychiatrists with general practitioners. However, there are many obstacles. According to Stuchlík and Wenigová who, within the project of Development of further education of physicians and psychiatrists on the issues of community care for mentally ill patients, mapped their mutual cooperation, the general practitioners see obstacles particularly in the low number of outpatient psychiatrists, insufficient feedback on the implemented examinations of the patient sent by the general practitioner to the psychiatrist and information on the specific patient's therapy. The outpatient psychiatrists see a problem in missing district specification, as the patient sent by the general practitioner is often treated by another psychiatrist already, which applies mostly to patients with addictions, as well as in bad estimation of suicidal risk by general practitioners. With respect to prevention of suicides and of relapsing suicides, the need to improve the knowledge of general practitioners and their skills of timely diagnosing the risk factors and to enhance the therapy of psychiatric disorders has turned out to be crucial (35), together with the implementation of the other measures stated above.

\section{Ethical Adherence Statement}

The authors of the submitted manuscript declare that all experiments are in compliance with valid legal regulations of the Czech Republic. The study complies with the principles of the Helsinki Declaration. The study was approved by the Ethical Commission of the Faculty of Health and Social Studies of the University of South Bohemia in České Budějovice.

\section{Acknowledgement}

This article is associated with research grant GAJU 130/2013/ S, implemented under the financial auspices of the Grant Agency of the University of South Bohemia in České Budějovice.

\section{REFERENCES}

1. Prošková E. Ethical and legal aspects of euthanasia. Kontakt. 2009;11(1):257-65. (In Czech.)

2. Knapp V. Theory of law. Prague: C.H. Beck; 1995. (In Czech.)

3. Pavlica K. Attitudes of students towards suicide. Kontakt. 2006;8(1):7280. (In Czech.)

4. Materstvedt LJ, Clark D, Ellershaw J, Førde R, Gravgaard AM, MüllerBusch HC, et al; EAPC Ethics Task Force. Euthanasia and physicianassisted suicide: a view from an EAPC Ethics Task Force. Palliat Med. 2003 Mar; 17(2):97-101; discussion 102-79.

5. Van Heeringen K. The Neurobiology of suicide and suicidality. Can J Psychiatry. 2003 Jun;48(5):292-300

6. Izáková L', Novotný V, Andréi I. Clinical aspects of suicidality. Čes Slov Psychiat. 2006;102(3):137-41. (In Czech.)

7. Mann JJ. The neurologiology of suicide. Nat Med. 1998 Jan;4(1):25-30.

8. Hjelmeland H, Hawton K, Nordvik H, Bille-Brahe U, De Leo D, Fekete $\mathrm{S}$, et al. Why people engage in parasuicide: a cross-cultural study of intentions. Suicide Life Threat Behav. 2002 Winter;32(4):380-93.

9. Economou M, Madianos M, Peppou LE, Theleritis C, Patelakis A, Stefanis C. Suicidal ideation and reported suicide attempts in Greece during the economic crisis. World Psychiatry. 2013 Feb;12(1):53-9.

10. Dörner K, Plog U. To act foolish is human. Prague: Grada; 1999. (In Czech.)

11. Vágnerová M. Current psychopathology for helping professions. Prague: Portál; 2014. (In Czech.)

12. Anthology of documents from the Project of foreign study visits related to the area of care for mental health (OP LZZ, CZ.1.04/5.1.01/12.00115) [Internet]. Prague: Centre for the development of care for mental health; 2011 [cited 2016 Jan 12]. Šteflová A. International aspect of the issue of mental health. Available from: http://www.cmhed.cz/centrum/publikace/. (In Czech.)

13. World Health Organization [Internet]. Copenhagen: WHO [cited 2016 Jan 28]. European Health for All database. Available from: http://www. 
euro.who.int/en/data-and-evidence/databases/european-health-for-alldatabase-hfa-db.

14. Dóci I, Hosák L, Kovářová M. Loneliness of old people as a social and medical problem. Čas Lék Čes. 2003;142(8):505-7. (In Czech.)

15. Probstová V, Peč O. Psychiatry for social workers. Prague: Portál; 2004 (In Czech.)

16. Hort V, Hrdlička M, Kocourková E, Malá E, et al. Child and adolescent psychiatry. Prague: Portál; 2000. (In Czech.)

17. Kessler RC, McGonagle KA, Zhao S, Nelson CB, Hughes M, Eshleman $\mathrm{S}$, et al. Lifetime and 12-month prevalence of DSM-III-R psychiatric disorders in the United States. Results from the National Comorbidity Survey. Arch Gen Psychiatry. 1994 Jan;51(1):8-19.

18. World Health Organization. Mental and Behavioural Disorders Team. Figures and facts about suicide. Geneva: WHO; 1999

19. Raboch J, Wenigová B, editors. Mapping of the status of psychiatric care and its tendency in compliance with strategic documents of the Czech Republic and foreign countries. Expert report from the project [Interent]. Prague: Czech Psychiatric Association; 2012 [cited 2016 Feb 28]. Available from: http://www.ceskapsychiatrie.cz/images/stories/ OZ_zkr_komplet.pdf. (In Czech.)

20. Winkler $\mathrm{P}$, editor. Reform of the system of psychiatric care: international policies, experience and recommendations. Activities of outpatient psychiatric facilities in 2012. Prague: Psychiatric Center Prague; 2013. (In Czech.)

21. Ministry of health. Health 2020 - National strategy of protection and support of health and prevention of diseases. Action Plan No. 3: Stress management. Prague: Ministry of health; 2013. (In Czech.)

22. Nechanská B. Activities of outpatient psychiatric facilities in 2012. Aktul Inf ÚZIS ČR. 2013;(32):1-10. (In Czech.)

23. Norheim AB, Grimholt TK, Ekeberg Ø. Attitudes towards suicidal behaviour in outpatient clinics among mental health professionals in Oslo. BMC Psychiatry. 2013;13:90.

24. Rodziński P, Rutkowski K, Sobański JA, Murzyn Białas A, Cyranka K, Grządziel K, et al. Reduction of suicidal ideation in patients undergoing psychotherapy in the day hospital for the treatment of neurotic and behavioral disorders and neurotic symptoms reported by them before the hospitalization. Psychiatr Pol. 2015;49(4):847-64.

25. Stanley B, Brown GK, Currier GW, Lyons C, Chesin M, Knox KL. Brief intervention and follow-up for suicidal patients with repeat emergency department visits enhances treatment engagement. Am J Public Health. 2015 Aug;105(8):1570-2.

26. Gart R, Kelly S. How illegal drug use, alcohol use, tobacco use, and depressive symptoms affect adolescent suicidal ideation: a secondary analysis of the 2011 Youth Risk Behavior Survey. Issues Ment Health Nurs. 2015 Aug;36(8):614-20.

27. Bae HC, Hong S, Jang SI, Lee KS, Park EC. Patterns of alcohol consumption and suicidal behavior: findings from the fourth and fifth Korea National Health and Nutritional Examination Survey (2007-2011). J Prev Med Public Health. 2015 May;48(3):142-50.

28. Schaffer M, Jeglic EL, Stanley B. The relationship between suicidal behavior, ideation, and binge drinking among college students. Arch Suicide Res. 2008;12(2):124-32.

29. Pompili M, Serafini G, Innamorati M, Dominici G, Ferracuti S, Kotzalidis GD, et al. Suicidal behavior and alcohol abuse. Int J Environ Res Public Health. 2010 Apr;7(4):1392-431.

30. Wetterling T, Schneider B. Alcohol intoxication and suicidality. Psychiatr Prax. 2013 Jul;40(5):259-63. (In German.)

31. Darvishi N, Farhadi M, Haghtalab T, Poorolajal J. Alcohol-related risk of suicidal ideation, suicide attempt, and completed suicide: a meta-analysis. PLoS One. 2015 May 20;10(5):e0126870.

32. Consoli A, Cohen D, Bodeau N, Guilé JM, Mirkovic B, Knafo A, et al. Risk and protective factors for suicidality at 6-month follow-up in adolescent inpatients who attempted suicide: an exploratory model. Can J Psychiatry. 2015 Feb;60(2 Suppl 1):S27-36.

33. Tarolla E, Caredda M, Tarsitani L, Maraone A, Biondi M. Predictive factors for further suicide attempts in individuals presenting to an emergency service for an attempted suicide. A one-year longitudinal study. Riv Psychiatr. 2015 Jan-Feb;50(1):28-33. (In Italian.)

34. Yen S, Fuller AK, Solomon J, Spirito A. Follow-up treatment utilization by hospitalized suicidal adolescents. J Psychiatr Pract. 2014 Sep;20(5):35362.

35. Stuchlík J, Wenigová B. Psychiatrists and general practitioners working at a common project. Psychiat Praxi. 2008;9(5):246. (In Czech.)

36. World Health Organization. Preventing suicide: a global imperative. Geneva: WHO; 2014.

37. Nagarajan R, Scutari M, Lèbre S. Bayesian networks in R: with applications in systems biology. New York: Springer; 2013.

38. Scutari, M, Denis, JB. Bayesian networks with examples in R. Chapman \& Hall; 2014.

39. Koski T, Noble JM. Bayesian networks: an introduction. Chichester: Wiley; 2009. Wiley series in probability and statistics.

Received January 4, 2016 Accepted in revised form September 22, 2017 